\title{
Kronologis Kisah Nabi Adam As dalam Tafsir Ibn Katsir
}

\section{Bustamar *)}

Institut Agama Islam Negeri Batusangkar, Sumatera Barat, Indonesia

E-mail:

bustamarputra95@gmail.com

\section{Fitri Yeni M Dalil}

Institut Agama Islam Negeri Batusangkar, Sumatera Barat, Indonesia

E-mail:

fitriyenidalil@yahoo.com

*) Corresponding Author

\begin{abstract}
Abstrak: Penelitian ini berdasarkan kisah Nabi Adam As yang berbagai fragmennya tersebar diberbagai surah dan ayat, menurut Ibn Katsir dalam Tafsir al-Qur`anul Adzim. Tujuan dari pembahasan ini adalah mengetahui sekaligus menyusun kronologis narasi kisah Nabi Adam As dari proses awal penciptaannya hingga ia keluar dari surga. Jenis penelitian yang digunakan adalah penelitian kepustakaan dengan menggunakan konten analisis. Dari kajian terhadap tafsir Ibn Katsir, kronologis kisah Nabi Adam As terbagi tiga, yaitu pertama, proses penciptaan Nabi Adam. Kedua kisah Adam As tinggal di surga dengan segala fasilitasnya. Ketiga, kisah Adam As dan istrinya dilarang mendekati pohon kuldi, yang kemudian aturan tersebut dilanggar oleh Adam As dan istrinya yang mengakibatkan Adam As dan istrinya dikeluarkan dari surga.
\end{abstract}

\begin{abstract}
This research is based on the story of the Prophet Adam As whose various fragments are scattered in various surahs and verses, according to Ibn Kathir in Tafsir alQur'anul Adzim. The purpose of this discussion is to know at the same time compile a chronological narrative of the story of the Prophet Adam As from the initial process of his creation until he came out of heaven. The type of research used is library research using content analysis. From the study of the interpretation of Ibn Kathir, the chronology of the story of the Prophet Adam As is divided into three, namely first, the process of the creation of the Prophet Adam. The second story of Adam As lived in heaven with all the amenities. Third, the story of Adam As and his wife were prohibited from approaching the kuldi tree, which was then broken by Adam As and his wife which resulted in Adam As and his wife being expelled from heaven.
\end{abstract}

Kata Kunci: Kisah, Adam, Ibn Katsir, Kronologis

\section{PENDAHULUAN}

Al-Qur`an merupakan objek yang selalu menarik untuk dikaji dari semua sisinya. Al-Qur`an memiliki berbagai aspek yang dapat dikaji baik secara universal maupun parsial termasuk yang berkaitan dengan kisah-kisah yang dimuat dalam al-Qur`an. Kisahkisah tersebut merupakan satu dari sekian banyak aspek yang membuktikan kemukjizatan al-Qur`an dan membuktikan kebenaran nubuwwah Rasulullah Saw. (Rofiqoh \& Ansori, 2017: 25)

Kisah-kisah tersebut memuat beragam permasalahan yang bisa dikaji secara substansial dan diuji kebenarannya berdasarkan fakta-fakta sejarah yang ditemukan. Kisah-kisah dalam al-Qur`an adalah sebenar- 
benarnya kisah, karena kisah-kisah tersebut pasti selalu sesuai dengan kenyataan yang terjadi. Kisah-kisah tersebut juga merupakan kisah-kisah terbaik, karena kisah-kisah tersebut mengandung nilai sastra dan makna yang tinggi. Selain itu, kisah-kisah dalam al-Qur`an juga merupakan kisah-kisah yang paling besar manfaatnya. (Rofiqoh \& Ansori, 2017: 26). Firman Allah;

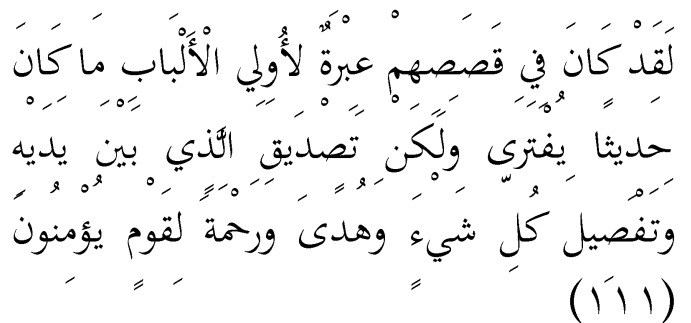

"Sesungguhnya pada kisah-kisah mereka itu terdapat pengajaran bagi orang-orang yang mempunyai akal. AlQur'an itu bukanlah cerita yang dibuat-buat, akan tetapi membenarkan (kitab-kitab) yang sebelumnya dan menjelaskan segala sesuatu, dan sebagai petunjuk dan rahmat bagi kaum yang beriman". (QS. Yusuf (12): 111)

Kisah-kisah dalam al-Qur`an bukanlah suatu cerita yang lengkap yang meliput berbagai aspek peristiwa. Seringkali tidak terdapat penyebutan tempat atau waktu kejadian, apalagi urutan ruang dan waktu. Sehingga diperlukan penejelasan lebih lanjut, yang disebut dengan Tafsir al-Qur`an.
Al-Qur`an dalam memaparkan kisah tidak tersusun secara kronologis sebagaimana buku sejarah. Sebagian kisah dalam suatu surah dan sebagian dimuat dalam surah lainnya, terkadang diungkapkan secara panjang lebar, terkadang secara garis besarnya saja. Misalnya kisah Nabi Adam As dalam al-Qur'an, yang dipaparkan tidak pada satu tempat/dalam satu surah saja, melainkan diberbagai ayat.hal tersebut bebrda dengan kisah Nabi Yusuf As yang terfokus pada satu surah saja.

Dalam al-Qur`an terdapat kisah Nabi Adam As, yang diceritakan berulang-ulang dalam berbagai surah dan ayat, seperti dalam surah AlBaqarah [2]: 30-39, Ali-Imran [3]: 59, Al-A'raf [7]: 11-25. Al-Hijr [15]: 2644. Al-Isra' [17]: 61- 65. Al-Kahfi [18]: 50. Thaha [20]: 115-124. Shad [38]: 71-85. Dalam Mu'jam alMufarras li al-Fazil Qur`an al-Karim, kata-kata Adam terdapat dalam 9 Surah, yang terdiri dari 25 ayat.(Nadim, 1945) Jika dilihat dari isi surah dan ayat yang mengandung kisah Nabi Adam As ada 8 Surah, yang terdiri dari 75 ayat. Dalam ayat tersebut adakalanya membicarakan tentang penciptaan Nabi Adam, kehidupannya 
di Surga dan latar belakang Nabi Adam turun dari Surga.

Kisah Nabi Adam pada surah tertentu urutannya tidak lengkap, surah al-Baqarah, sebagai surah kedua berdasarkan tartib Utsmani, menjelaskan kisah Nabi Adam setelah Allah menciptakannya, dan tidak pernah membicarakan bahwa Adam diciptakan dari tanah. Hanya saja menjelaskan pemberitaan Allah kepada Malaikat tentang akan diciptakan makhluk baru sebagai khalifah di bumi, pengetahuan Adam melebihi pengetahuan Malaikat, perintah sujud, pembangkangan iblis, suruhan Allah terhadap Adam bersama istrinya tinggal di surga dan terakhir penurunan Adam dari surga. Dalam surah alBaqarah tidak ada menjelaskan tentang penciptaan Hawa, tiba-tiba langsung godaan iblis. Sedangkan mengenai penciptaan Nabi Adam tersebut dipaparkan dalam surah lain.

Dengan demikian diperlukan rentetan kisah yang lengkap, agar lebih mudah dipahami. Walaupun ada yang menyatakan kisah itu tidak harus berurutan dari awal hingga akhir. Ada sebuah kisah itu menggunakan alur maju (linier), ada yang menggunakan alur mundur dan ada juga yang menggunakan alur bolak balik. Orang yang menggunakan tiga alur tersebut memiliki keunggulan masing-masing. Kemudian dari pada itu agar al-Qur`an memiliki maknanya yang utuh maka perlu adanya rentetan atau urutan dari kisah itu sendiri. Dengan kata lain rentetan kisah Nabi Adam As mulai dari penciptaan hingga tahapan selanjutnya.

Pada penelitian ini penulis menggunakan Kitab Ibn Katsir sebagai sumber utama. Disebabkan kitab Tafsir Ibnu Katsir memiliki keistimewaan dalam beberapa aspek, seperti dalam hal ketelitian sanadnya, kesederhanaan ungkapannya, dan kejelasan ide pemikirannya. Di samping itu dalam penafsirannya Ibn Katsir lebih mengedepankan penafsiran dengan alQur`an itu sendiri, jika itu tidak ditemukan di ayat lain maka beranjak pada Hadits, jika tidak ditemukan dalam Hadits, maka didukung dengan pendapat Sahabat Nabi Saw, jika tidak ada pendapat Sahabat tentang hal yang demikian maka beralih pada tabi'in.

\section{METODE}

Penelitian ini merupakan penelitian kepustakaan atau library 
research. Jenis penelitian yang sisi-Nya sebelum Allah Swt digunakan adalah penelitian menciptakan mereka, sebagaimana kepustakaan. Sebagai penelitian tafsir firman Allah, و إذ قال ربك للملئكة "yakni tentang kisah nabi Adam As, teknik ingatlah wahai Muhammad, saat pengumpulan dan analisis data ayat- Rabbmu berfirman kepada para ayat al-Qur`an melalui term Adam, Malaikat, dan kabarkanlah hal ini digunakan pendekatan tafsir tematik.

\section{HASIL DAN PEMBAHASAN}

\section{Penciptaan Nabi Adam As}

\section{Pengkabaran Allah Tentang Penciptaan Khalifah /Makhluk Baru di Bumi}

QS. al-Baqarah/2: 30,

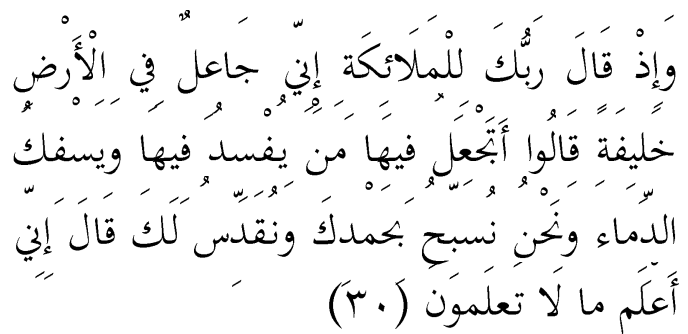

Ingatlah ketika Tuhanmu berfirman kepada Para Malaikat: "Sesungguhnya aku hendak menjadikan seorang khalifah di muka bumi." mereka berkata: "Mengapa Engkau hendak menjadikan (khalifah) di bumi itu orang yang akan membuat kerusakan padanya dan menumpahkan darah, Padahal Kami Senantiasa bertasbih dengan memuji Engkau dan mensucikan Engkau?" Tuhan berfirman: "Sesungguhnya aku mengetahui apa yang tidak kamu ketahui."

Ibn Katsir (2017: 518) menafsirkan ayat ini bahwa Allah Swt mengabarkan karunia-Nya kepada Bani Adam dengan menyebut nama mereka di tengah para Malaikat yang berada di kepada kaummu. Ibn Jarir menyebutkan keterangan dari sebagian pakar Bahasa arab, yaitu Abu Ubaidah yang mengklaim bahwa kata إذ merupakan zaidah (tambahan). Perkiraan kalimatnya ialah وقال ربك Namun Ibn Jarir membantahnya. AlQurthubi mengatakan, seluruh ahli tafsir juga membantahnya, bahkan azZajjaj sampai mengatakan "ini sebuah kelancangan dari Abu Ubaidah".

$$
\text { yakni, suatu }
$$

kaum yang sebagian meneruskan kaum sebelumnya, abad demi abad generasi demi generasi, sebagaimana yang Allah Swt firmankan, وهو الذى جعلكم خلَئف (QS. al-An'am: 165). Dia Allah berfirman, .....ويجعلكم خلفاء الأرض.. ولو (QS. an-Namal: 62) dan firman-Nya نشاء لجعلنا منكم ملائكة فى الأرض يخلفون (QS. az-Zukhruf: 60) dan firman-Nya, فخلف من بعدهم خلف (QS. Maryam: 59). Dan dibaca secara syadz (aneh); إنى جاعل فى مهى disebutkan oleh azZamaksyari dan lainnya serta 
dinukilkan oleh al-Qurthubi dari Zaid bin Ali. (Katsir, Jilid I, 2017: 519)

\section{Proses Penciptaan Nabi Adam As}

QS. Ali-Imran/3: 59

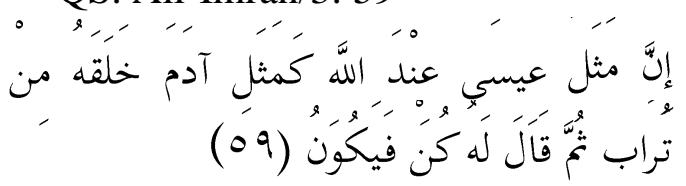

"Sesungguhnya misal (penciptaan)"Isa di sisi Allah, adalah seperti (penciptaan) Adam. Allah menciptakan Adam dari tanah, kemudian Allah berfirman kepadanya: "Jadilah" (seorang manusia), Maka jadilah Dia”.

Pada ayat ini Ibn Katsir tidak menjelaskan makna نراب secara detail, dari lafaz ayat Adam kejadian awalnya memang dari تراب namun dalam penafsirannya ayat tersebut membahas tentang kisah Nabi Isa yang tidak memiliki bapak yang sama dengan kejadian Nabi Adam As. Namun pada surah al-Hajj/22: 5, Allah menjelaskan

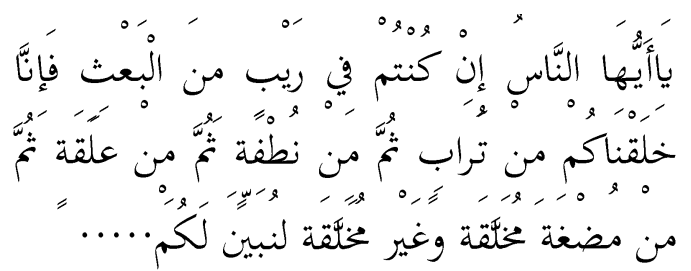

"Hai manusía," jiká kamu" dalam keraguan tentang kebangkitan (dari kubur), Maka (ketahuilah) Sesungguhnya Kami telah menjadikan kamu dari tanah, kemudian dari setetes mani, kemudian dari segumpal darah, kemudian dari segumpal daging yang sempurna kejadiannya dan yang tidak sempurna, agar Kami jelaskan kepada kamu..."
نراب disini adalah asal mula kejadian Adam As yaitu diciptakan dari tanah, kemudian anak keturuananya dari air yang hina. (Katsir, 2017: 112. Jilid 7)

QS. al-Hijr/15: 26,

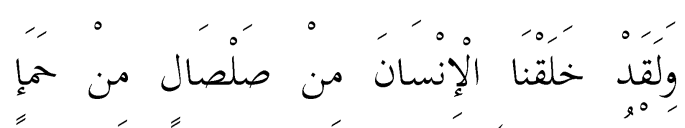
مسنون (rT)

"Dan Sesungguhnya Kami telah menciptakan manusia (Adam) dari tanah liat kering (yang berasal) dari lumpur hitam yang diberi bentuk".

Ibn abbas As, Mujahid dan Qatadah berkata: "Yang dimaksud dengan shalshal disini ialah tanah liat kering. Secara lahiriah ia seperti firman Allah Swt, خَلَقَ الْإِنْسَانَ مِنْ صَلْصَالٍ كَالْفَفَّارِ ( ا ( ) وَخَلَقَ الْجَانَّ مِنْ مَارِجِ مِنْ نَارِ (QS. Ar-Rahman: 14-15). Pendapat dari Mujahid juga صلصنل ialah tanah yang berbau busuk. Namun penafsiran ayat dengan ayat lain lebih utama.

Firman Allah من حملإ مسنون, yakni tanah liat kering dari lumpur hitam sedangkan sسنون artinya halus atau licin. Karena inilah, diriwayatkan dari Ibn Abbas bahwa ia berpendapat, 'ia adalah tanah liat yang basah'. Juga diriwayatkan dari Ibn Abbas, Mujahid dan adh-Dhahak, 'bahwa yang dimaksud حمنا مسنون, ialah tanah yang berbau busuk. Ada pendapat yang lain 
bahwa yang dimaksud dengan حماب مسنون, disini ialah yang diberi bentuk. (Ibn Katsir, jilid 6, hal.17-18).

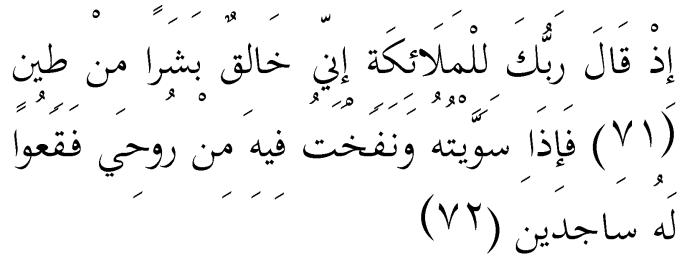

"(ingatlah) ketika Tuhanmu berfirman kepada Malaikat: "Sesungguhnya aku akan menciptakan manusia dari tanah". Maka apabila telah Kusempurnakan kejadiannya dan Kutiupkan kepadanya roh (ciptaan)Ku; Maka hendaklah kamu tersungkur dengan bersujud kepadaNya" (QS. Shad/38: 71-72).

Allah menciptakannya dengan tangan-Nya agar Iblis tidak menyombongkan diri darinya dan agar Dia berkata 'kamu menyombongkan diri dari apa yang Aku ciptakan dengan tangan-Ku, padahal Aku sendiri tidak menyombongkan diri darinya'.

Allah menciptakannya sebagai manusia, ia berbentuk jasad dari tanah liat selama 40 hari sejak hari Jum'at, para Malaikat melewatinya, mereka terkejut karena melihatnya. Yang paling terkejut dari mereka adalah Iblis, ia melewatinya dan memukulnya, hingga jasad itu mengeluarkan suara, seperti tanah bejana tanah liat yang berdenting, firman Allah, مِنْ صَتْصلٍ
كَالْفَذَّارِ (QS. ar-Rahman/55: 14). Iblis berkata, 'kamu diciptakan untuk suatu perkara'. Lalu ia masuk masuk ke dalam mulutnya dan keluar dar duburnya, ia berkata kepada Maliakat, jangan takut terhadapnya, sesungguh Rabb kalian tidak membutuhkan sedangkan ia ini berongga. Bila aku menguasainya, benar-benar aku akan menghancurkannya. (Katsir, Jilid I, 2017: 540)

Manakala sudah tiba masanya Allah Swt meniupkan ruh padanya, Allah berfirman kepada Maliakat, 'bila Aku meniupkan ruh-Ku padanya maka bersujudlah kalian kepadanya'. Ketika Allah meniupkan ruh-Nya dan ruh itu langsung masuk melalui kepalanya maka ia bersin. Malaikat berkata kepadanya, 'ucapkan Alhamdulillah'. Ia pun mengucapkannya. Maka Allah Swt berfirman, 'semoga Rabbmu merahmatimu'. Ketika ruh masuk ke sepasang matanya, ia melihat buahbuahan di Surga. Ketika ruh masuk ke dalam rongga perutnya, ia ingin makan, maka ia terburu-buru melompat menuju buah Surga sebelum ruh sampai di kedua kakinya. Hal itu ketika Allah berfirman خُلقَ الإنْسنُ مِن عَجَلٍ (QS. al-Anbiya`/21: 37) 
Pengetahuan Adam As Melebihi
Pengetahuan Malaikat

QS. al-Baqarah/2: 31-33,

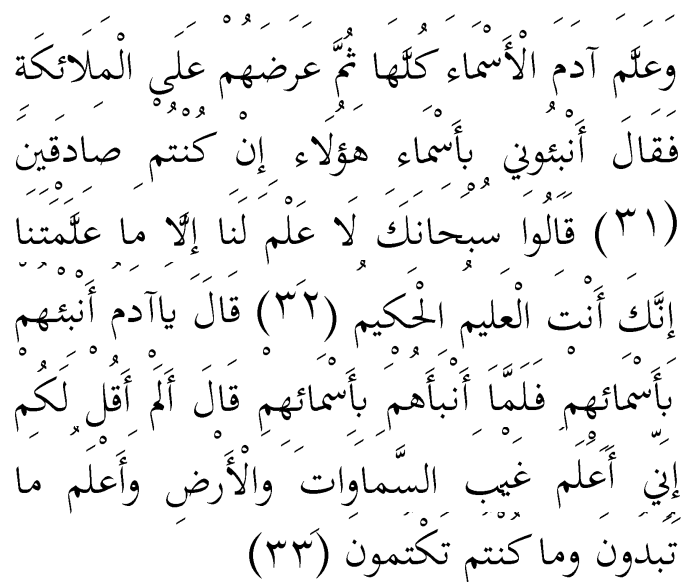

"Dan Dia mengajarkan kepada Adam Nama-nama seluruhnya, (benda-benda) kemudian mengemukakannya kepada Para Malaikat lalu berfirman: "Sebutkanlah kepada-Ku nama benda-benda itu jika kamu mamang benar orang-orang yang benar!" Mereka menjawab: "Maha suci Engkau, tidak ada yang Kami ketahui selain dari apa yang telah Engkau ajarkan kepada kami; Sesungguhnya Engkaulah yang Maha mengetahui lagi Maha Bijaksana." Allah berfirman: "Hai Adam, beritahukanlah kepada mereka Namanama benda ini." Maka setelah diberitahukannya kepada mereka Nama-nama benda itu, Allah berfirman: "Bukankah sudah Ku katakan kepadamu, bahwa Sesungguhnya aku mengetahui rahasia langit dan bumi dan mengetahui apa yang kamu lahirkan dan apa yang kamu sembunyikan?

Dalam ayat ini Allah Swt menyebutkan kemuliaan Adam As atas para Malaikat. Karena Allah Swt secara khusus mengajarkan ilmu khusus tentang nama-nama segalaga sesuatu sementara untuk Malaikat tidak. Ini berlangsung setelah para Malaikat sujud kepada Adam As. Allah mendahulukan ayat ini karena ada hubungan antara ayat ini dengan ketidaktahuan Malaikat tentang hikmah diciptakannya khalifah manakala mereka menanyakan hal itu kepada Allah Swt, maka Allah Swt mengabarkan kepada mereka bahwa Dia mengetahui apa yang tidak mereka ketahui. Untuk itu selanjutnya Allah Swt menyebutkan ayat ini setelah itu untuk menjelaskan kemuliaan Adam As karena Allah Swt telah memberinya kelebihan daripada mereka dalam hal علّم آدم الأسماءء ilmu. Allah Swt berfirman كلها. (Katsir, Jilid I, 2017: 530)

As-Suddi mengatakan, dari orang yang menyampaikan hadits kepadanya علّم آدم dari Ibn Abbas tentang ayat الأسمآء كلها, ia berkata: Dia menunjukkan kepadanya nama-nama anaknya, satu persatu dan nama-nama hewan, dikatakan kepadanya, 'ini keledai, ini unta, ini kuda.

Adh-Dahk mengatakan dari Ibn Abbas ia berkata علّم آدم الأسمآء كلها, yaitu nama-nama benda yang diketahui oleh manusia, hewan, langit, bumi, daratan, 
lautan, unta, keledai dan nama-nama makhluk lainnya. Ibn Abi Hatim dan Ibn Jarir meriwayatkan dari hadits 'Asyim bin Kulaib, dari Sa'id bin Ma'bad, dari Ibn Abbas, ia berkata: علّم ,آدم الأسماء كلها Dia mengajarkan kepadanya nama piring besar dan periuk. Ia berkata, 'Ya, sampai-sampai kentut pun ia ajarkan'. (Katsir, Jilid I, 2017: 530)

As-Suddi dalam tafsirnya mengatakan dari Abu Malik, dari Abu Shaleh dari Ibn Abbas dan dari Murrah, Ibn Mas'ud dan beberapa orang و علم sahabat tentang firman Allah Swt, yakni, kemudian para makhluk disodorkan kepada para malaikat. Ibn Juraij mengatakan dari Mujahid tentang ayat نُمَّْ عَرَضَتُهُمْ Yakni, benda-benda yang punya nama itu disodorkan kepada para Malaikat. (Katsir, Jilid I, 2017: 532)

Ibn Jarir mengatakan, dari alHasan dan Qatadah, keduanya berkata, "Allah mengajarkan kepadanya namanama segala sesuatu, Dia menyebutkan segala sesuatu dengan nama-namanya dan umat demi umat ditampakkan kepadanya'. Dengan sanad ini dari alHasan dan Qatadah tentang firman Allah إن كنتم صدقين. Sesungguhnya Aku tidak menciptakan makhluk melainkan kalian lebih tahu darinya, maka dari itu beritahukan kepadaku tentang namanama benda tersebut jika kalian memang benar.

Adh-Dhahak mengatakan dari Ibn Abbas إن كنتم صدقين. Yakni, jika kalian benar-benar tahu untuk apa Aku menciptakan seorang khlifah di muka Bumi. As-Suddi meriwayatkan dari Abu Malik dan Abu Shaleh dari Ibn Abbas dan dari Murrah dan dari Ibn Mas'ud dan beberapa orang sahabat, إن كنتم صدقين Bahwa Bani Adam berbuat kerusakan di Bumi dan Menumpahkan darah.

Ibn Jarir berkata, "pendapat yang paling mendekati kebenaran dalam hal ini ialah takwil Ibn Abbas dan mereka yang sependapat dengannya. Makna dari ayat itu ialah bahwa Allah Swt berfirman 'beritahukanlah kepada-Ku nama dari benda-benda yang $\mathrm{Aku}$ sodorkan kepada kalian wahai para Malaikat yang berkata, 'apakah Engkau menjadikan makhluk di bumi orang yang akan membuat kerusakan padanya dan menumpahkan darah dari selain kami atau sebagian dari kami, sementara selama ini kami bertasbih dengan memuji-Mu dan mensucikan- 
Mu?, bila kalian memang orang-orang yang benar dalam apa yang kalian katakana, bahwa bila Aku menciptakan khalifah-Ku di Bumi selain kalian maka anak-anaknya akan mendurhakai$\mathrm{Ku}$, berbuat kerusakan dan menumpahkan darah, dan bila Aku menjadikan kalian di Bumi maka kalian akan menaati-Ku, mengikuti perintah-Ku dengan mengagungkan dan mensucikan-Ku. Bila terhadap nama-nama apa yang Aku bentangkan kepada kalian saja kalian tidak tahu padahal kalian menyaksikan mereka, maka apalagi terhadap perkara yang tidak ada perkara-perkara yang akan terjadi tentu kalian lebuh tidak tahu lagi”. (Katsir, Jilid I, 2017: 533)

Firman Allah Swt, قالو اسبختك لا علم لنآ إلّا ما علّمتنا إنّّك العليم الحكيم Ini adalah pensucian dari Malaikat untuk Allah Swt, bahwa seseorang tidak mungkin mengetahui sebagian ilmu-Nya kecuali bila Dia kehendaki dan tidak mungkin mereka mengetahui sesuatu kecuali yang Allah Swt ajarkan kepada mereka. Oleh karena itu mereka

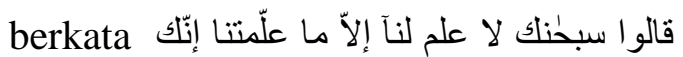
. Yakni, Maha Mengetahui segala sesuatu, Maha Bijaksana pada penciptaan, perintah dan pengajaran-
$\mathrm{Mu}$ kepada siapa yang Engkau kehendaki serta penolakan-Mu terhadap siapa yang Engkau kehendaki, Engkau memilki hikmah di balik semua itu dan keadilan yang sempurna. (Katsir, Jilid I, 2017: 533)

\section{Perintah Sujud Kepada Nabi Adam As}

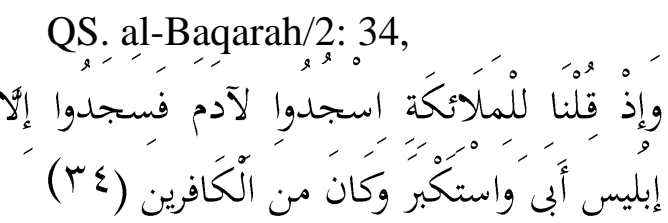
"Dan (ingátlah) kétika Kami berfirmań kepada Para Malaikat: "Sujudlah kamu kepada Adam, "Maka sujudlah mereka kecuali Iblis; ia enggan dan takabur dan adalah ia Termasuk golongan orang-orang yang kafir".

Ini adalah kemuliaan besar dari Allah Swt untuk Adam As yang Dia karuniakan kepada anak cucunya. Allah Swt mengabarkan bahwa Dia memerintahkan para Malaikat untuk sujud kepada Adam As. Banyak juga hadits yang menunjukkan hal itu, di antaranya hadits syafa'at yang sudah disebutkan, serta hadist Musa As, 'Wahai Rabbku perlihatkan kepadaku Adam yang telah mengeluarkan kami dan dirinya dari Surga'. Ketika Musa bertemu Adam, ia berkata, 'kamu Adam yang telah ciptakan dengan tangan-Nya, Allah tiupkan ruh-Nya ke 
dalam dirinya dan Allah perinthakan Maliakat untuk bersujud kepadanya'

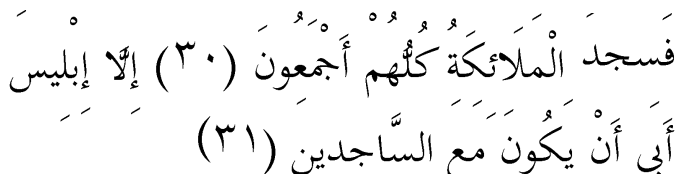

"Maka bersujudlah para Malaikat itu semuanya bersama-sama. Kecuali iblis. ia enggan ikut besama-sama (malaikat) yang sujud itu. (QS. alHijr/15: 30-31)

Ibils menolak seraya menyombongka diri dan ia termasuk golongan yang kafir. Allah Swt berfirman kepadanya, 'apa yang menghalangimu untuk bersujud kepada apa yang Aku ciptakan dengan kedua tangan-Ku saat Aku perintahkan kepadamu?' Iblis menjawab, 'aku lebih baik darinya, aku tidak akan sujud kepada apa yang Engkau ciptakan dari tanah. Allah berfirman;

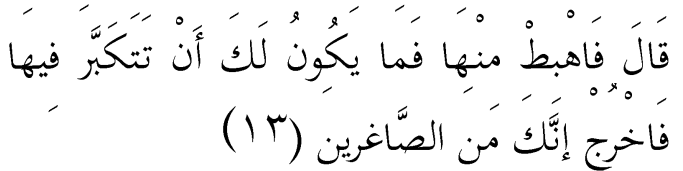

"Allah berfirman: "Turunlah kaḿu dari surga itu; karena kamu sepatutnya menyombongkan diri di dalamnya, Maka keluarlah, Sesungguhnya kamu Termasuk orang-orang yang hina".

Ketika Allah Swt memerintahkan para Malaikat untuk bersujud kepada Adam, perintah itu mencakup Iblis, karena ia sekalipun bukan dari golongan Malikat, tapi ia menyerupai mereka dan menyerupai perbuatan mereka. Oleh karena itu ia masuk dalam perintah Allah Swt tersebut dan dicela kerena menyalahi perintah Allah. Karenanya Muhammad bin Ishaq mengatakan dari Khallad, dari Atha' dari Thawus, dari Ibn Abbas, ia berkata, 'Iblis sebelum bermaksiat termasuk golongan Malaikat, namanya adalah 'Azazil, ia termasuk penduduk bumi, tergolong Malaikat yang paling giat dan paling banyak ilmunya hingga hal itu membuatnya takabur. Ia bersal dari sebuah daerah bernama Jin. Riwayat senada dari Khallad, dari Atha' dari Thawus atau Mujahid dari Ibn Abbas atau selainnya.(Katsir, jilid I, 2017: 542)

Ibn Jarir, dari al-Hasan, ia berkata, 'Iblis bukan dari malaikat sekejap pun. Ia adalah asal Jin sebagaimana Adam asal manusia'. Ini sanad shahih dari alhasan. Ucapan yang sama dikatakan oleh Abdurrahman bin Zaid bin Aslam. Syahr bin Hausyab berkata, 'iblis termasuk Jin yang diusir para Malaikat. Ia ditahan oleh beberapa Malaikat lalu dibawa ke langit. Diriwayatkan oleh Ibn Jarir.

Qatadah berkata tentang firman Allah Swt, وإذ قلنا للملئكة اسجدوا لأدم. Ketaatan itu untuk Allah. Adapun 
sujud itu, maka dengannya Allah memuliakan Adam dengan memerintahkan para Malaikat untuk sujud kepadanya. (Katsir, Jilid I, 2017:

Qatadah berkata tentang firman Allah, فسجدوا إلّا إبليس أبى واستكبر وكان من الكفرين. Musuh Allah - Iblis - dengki kepada Adam atas kemuliaan yang Allah berikan kepadanya, ia berkata, 'aku dari api sedangkan ia dari tanah'. maka awal dosa mereka adalah kesombongan, musuh Allah ini menyombongkan diri sehingga ia menolak untuk sujud kepada Adam. (Katsir, jilid, 2017: 543)

\section{Kehidupan Nabi Adam As di Surga}

QS. al-Baqarah/2: 35-36

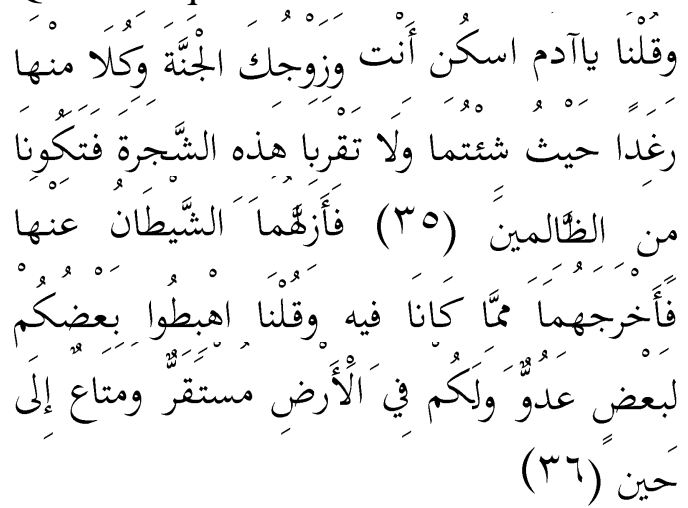

Dan Kami berfirman: "Hai Adám, diamilah oleh kamu dan isterimu surga ini, dan makanlah makananmakanannya yang banyak lagi baik dimana saja yang kamu sukai, dan janganlah kamu dekati pohon ini, yang menyebabkan kamu Termasuk orangorang yang zalim. Lalu keduanya digelincirkan oleh syaitan dari surga itu dan dikeluarkan dari Keadaan semula dan Kami berfirman: "Turunlah kamu! sebagian kamu menjadi musuh bagi yang lain, dan bagi kamu ada tempat kediaman di bumi, dan kesenangan hidup sampai waktu yang ditentukan."

Allah berfirman dalam rangka mengabarkan bentuk penghargaan-Nya kepada Adam setelah Dia memerintahkan para Malaikat untuk sujud kepadanya, maka mereka sujud kecuali Iblis. Allah mengizinkan Adam untuk masuk Surga dan tinggal disana sesukanya, makan darinya sesukanya, "yang banyak lagi baik” yakni, dengan tenang, lapang dan baik. (Katsir, Jilid I, 2017: 547)

Al-Hafiz Abuh Bakar bin Mardawaih meriwayatkan dari hadits Muhaamad bin Isa ad-Damaghani, dari Abu Zar, ia berkata, "aku berkata, 'Wahai Rasulullah, apakah menurutmu Adam itu seorang Nabi?' Beliau menjawab, Ya. Ia seorang Nabi dan Rasul yang Allah ajak berbicara mendahului siapapun, Dia berfirman , اسكن أنت وزوجك الجنّة. ”

Ada perbedaan pendapat mengenai letak Surga yang ditempati oleh Adam, apakah terletak di langit atau di bumi? Kebanyakan ulama berpendapat yang pertama. Sementara al-Qurthubi 
menyebutkan pendapat dari Mu'tazilah dan Qadariyah, bahwa surga tersebut ada di bumi. Konteks ayat tersebut menunjukkan bahwa Hawa diciptakan sebelum Adam masuk ke dalam Surga dan hal ini dikatakan dengan jelas oleh Muhammad bin Ishaq, ia berkata, "Setelah menyalahkan Iblis, Dia menghadap kepada Adam dan sebelumnya Dia sudah ajarkan seluruh nama-nama. (Katsir, Jilid I, 2017: 548)

Kemudian Adam dibuat mengantuk sebagaimana disampaikan oleh Ahli Kitab dari kalangan Ahli Taurat dan Ahli Ilmi lainnya. Dari Ibn Abbas dan lainnya, kemudian Allah mengambil salah satu tulang rusuk Adam sebelah kiri dan menutup tempatnya dengan daging. Saat itu Adam sedang tidur. Adam belum bangun hingga Allah menciptakan istrinya, Hawa. Dari tulang rusuknya. Allah menciptakannya dalam bentuk seorang wanita agar Adam menjadi tenang kepadanya. Ketika Adam bangun dari tidur, ia melihat Hawa di sampingnya, maka ia berkata, sebagaimana yang mereka katakan Allah lebih tahu, 'daging, darah dan ruhku'. Maka Adam merasa tenang kepadanya, manakala Allah menikahkan Adam dengannya, Dia menjadikan hati Adam merasa tenang kepadanya, lalu Allah berfirman;

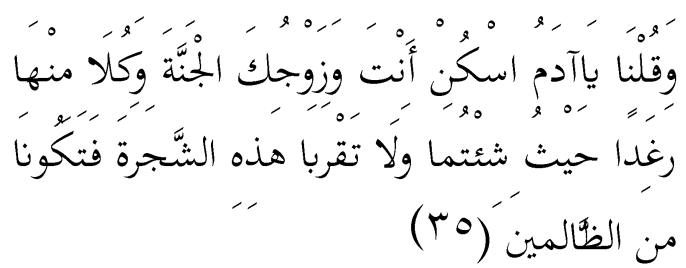

Dan Kami berfirman: "Hai'Adam, diamilah oleh kamu dan isterimu surga ini, dan makanlah makananmakanannya yang banyak lagi baik dimana saja yang kamu sukai, dan janganlah kamu dekati pohon ini, yang menyebabkan kamu Termasuk orangorang yang zalim.

ولا تقربا هذه Adapun firman-Nya الشجرة, maka itu adalah ujian dari Allah untuk Adam. Para Ulama berselisih pendapat tentang apa pohon tersbut. As-Suddi mengatakan dari seorang yang menyampaikan kepadanya dari Ibn Abbas, 'pohon yang dilarang untuk di makan Adam adalah anggur. Hal senada juga dikemukakan oleh Sa'id bin Jubair, as-Suddi, asy-Sya'bi, Ja'dah bin Hubairah dan Muhammad bin Qais. As-Suddi dalam sebuah riwayat yang disebutkannya juga mengatakan, dari Abu Malik dan Abu Shaleh, dari Ibn Abbas, dari Murrah, dari Ibn Mas'ud ولا تقربا هذه dan beberapa orang sahabat, الثجرة, yakni, pohon anggur, namun kaum Yahudi mengklaim pohon yang 
dimaksud adalah pohon gandum. Mujahid, ولا تقربا هذه الثجرة, yaitu pohon (Katsir, Jilid I, 2017: 549)

Ibn Jarir berkata, seorang laki-laki dari bani Tamim menuturkan tin. Qatadah dan Ibn Juraij juga berkata demikian.

Abu Ja'far ar-Razi berkata, dari arkepadaku, bahwa Ibn Abbas pernah Rabi' bin Anas, dari Abu al-Aliyah, menulis surat kepada Abu al-Jalad untuk menanyakan perihal pohon yang dimakan Adam dan pohon tempat Adam bertaubat. Maka Abu al-Jalad membalas suratnya, 'kamu bertanya kepadaku tentang pohon yang dimakan Adam, adalah pohon gandum. 'barang siapa yang memakan pohon tersebut maka ia akan buang kotoran, padahal seharusnya di Surga tidak ada kotoran'. Abdurrazaq berkata, Umar bin Abdirrahman bin Muhrib menuturkan kepada kami, ia berkata, aku mendengar Wahb bin Munabbih Sedangkan pohon tempat Adam berkata, 'Allah menyuruh Adam dan bertaubat adalah pohon zaitun'. Hasan istrinya tinggal di Surga dan al-Bashri, Wahb bin Muanbbih, melarangnya memakan (buah) dari Athiyyah al-'Aufi, Abu Malik, sebuah pohon. Pohon tersebut Muharib bin Ditsar dan Abdurrahman mempunyai dahan yang bercabang satu bin Abi Laila juga menafsirkan demikian. (Katsir, Jilid I, 2017: 549)

Muhammad bin Ishaq meriwayatkan dari beberapa orang Yaman, dari Wahb bin Munabbih, ia berkata, 'pohon yang dimaksud adalah pohon gandum. Akan tetapi satu biji pohon gandum di Surga besarnya seperti paha sapi, rasanya lebih lembut dari keju dan lebih manis daripada madu'. Sufyan ats-Tsauri berkata, dari ولا تقربا هذه Husain dari Abu Malik, الثجرة, maksudnya adalah pohon kurma. Ibn Jarir mengatakan dari sama lain. Pohon tersebut juga memiliki buah yang dimakan oleh para Malaikat karena mereka kekal di dalamnya. Itulah pohon yang Allah larang Adam dan istrinya untuk memakannya. (Katsir, Jilid I, 2017: 550)

\section{Keluarnya Nabi Adam dari Surga}

Godaan Syaitan Terhadap Adam As dan Istrinya (Hawa) Hingga Memakan Buah Terlarang

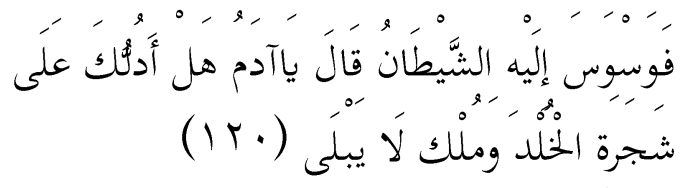


"Kemudian syaitan membisikkan pikiran jahat kepadanya, dengan berkata: "Hai Adam, maukah saya tunjukkan kepada kamu pohon khuldi dan kerajaan yang tidak akan binasa?"(QS. Thaha/20: 120).

yakni bersumpah keduanya dengan nama Allah إنّى لكما لمن النّصحين, sesungguh aku berada disini lebih dahulu dari kalian berdua, dan aku lebih mengetahui tempat ini. Iblis bersumpah kepada keduanya mengenai hal itu dengan nama Allah, sehingga keduanya tertipu. Dan terkadang seseorang bias tertipu jika disebut nama Allah. Qatadah berpendapat mengenai ayat ini bahwa Iblis bersumpah dengan nama Allah, 'sesungguhnya aku diciptakan sebelum kalian, aku lebih mengetahui daripada kalian, maka ikutilah aku, niscaya aku akan membimbing kalian'. Sebagian ahli ilmu berkata, 'barang siapa yang menipu kami dengan menyebut nama Allah, kami akan tertipu'. (Katsir, Jilid IV, 2017: 457)

\section{Adam dan Istrinya Mohon Ampunan} Kepada Allah

QS. al-Baqarah/2: 37,

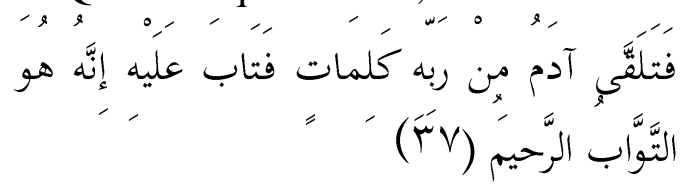

"Kemudian Adam menerima beberapa kalimat dari Tuhannya, Maka Allah menerima taubatnya. Sesungguhnya Allah Maha Penerima taubat lagi Maha Penyayang.

Ada yang berkata, bahwa kalimat dalam ayat ini ditafsirkan oleh firman Allah, قَالَ رَبَنَّا ظَلَنَنَا أَنْفُسَنَا وَإِنْ لَمْ تَغْفْرْ لَنَا

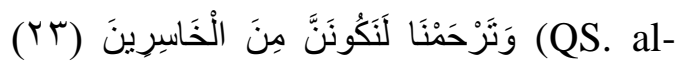
A'raf/7: 23). Ini diriwayatkan dari Mujahid, Sa'id bin Jubair, Abu alAliyah, ar-Rabi' bin Anas, al-Hasan, Qatadah, Muhammad bin Ka'ab alQurazhi, Khalid bin Ma'dan, Atha' alKhurasani dan Abdurraman bin Zaid bin Aslam. Abu Ishaq as-Sabi'I berkata, dari seorang laki-laki, dari Bani Tamim, ia berkata, 'aku datang menemui Ibn Abbas dan bertanya kepadanya, kalimat apakah yang Adam terima dari Rabbnya? Ibn Abbas menjawab, Adam diajari ilmu mengenai ibadah haji.

Sufyan ats-Tsauri berkata, dari Ubaid bin Umair, ia berkata, 'Adam berkata, Wahai Rabb, kesalahan yang telah aku lakukan, apakah termasuk salah sesuatu yang telah Engkau tuliskan sebelum Engkau menciptakankuatau sesuatu yang aku buat sendiri dari diriku? Allah menjawab, sesuatu yang telah aku tulis atasmu sebelum Aku menciptakanmu, Adam berkata, sebagaimana Engkau 
telah menulisnya atasku maka rahasia kitab-Nya. (Katsir, jilid I, 2017: ampunilah aku'. Itulah firman Allah 558)

. فتلقّ آدم من ربّه كلمنت فتاب عليه I, 2017: 554)

\section{Keluarnya Adam Bersama Istrinya dari Surga}

QS. al-Baqarah/2: 38,

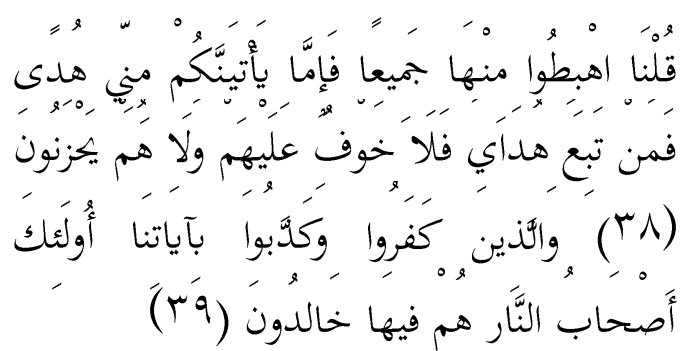

Kami berfirman: "Turunlah kamu semuanya dari surga itu! kemudian jika datang petunjuk-Ku kepadamu, Maka barang siapa yang mengikuti petunjuk-Ku, niscaya tidak ada kekhawatiran atas mereka, dan tidak (pula) mereka bersedih hati". Adapun orang-orang yang kafir dan mendustakan ayat-ayat Kami, mereka itu penghuni neraka; mereka kekal di dalamnya.

Penurunan yang kedua ini disebutkan karena berkaitan dengan yang sedisebutkan sesudahnya, yaitu adanya makna yang berbeda. Sebagian dari mereka berkata, ia adalah pengulangan yang berfungsi sebagai penegasan, seperti perkataan, "berdirilah, berdirilah". Yang lain berkata penurunan pertama dari Surga ke langit paling bawah. Penurunan kedua dari langit paling bawah ke bumi. Wallahu a'lam tentang rahasia-
Allah berfirman dalam rangka mengabarkan tentang perintah-Nya kepada Adam, istrinya dan Iblis hingga Dia menurunkan mereka dari Surga. Maksud anak keturunan Adam yaitu Allah akan menurunkan kitab-kitab dan mengutus Nabi-Nabi serta Rasul-Rasul, sebagaimana yang dikatakan oleh Abu al-Aliyah, al-Huda (petunjuk) adalah para Nabi, para Rasul, ayat-ayat dan keterangan. Muqatil bin Hayyan berkata, al-Huda adalah Muhammad. Al-Hasan berkata, al-Huda adalah alQur`an. Kedua pendapat ini sama-sama shahih dan pendapat Abu al-Aliyah lebih umum.

فَمَنْ نَبْعَ هُدَاى yakni barang siapa yang mengikuti kitab-kitab yang Aku turunkan dan Rasul-Rasul yang Aku utus. فَلاَخَوْنَ عَلَيْهِْْ "Niscaya tidak ada kekhawatiran atas mereka”. Yakni dalam perkara akhirat yang mereka hadapi. وَلاَهُم يَحْزَنون "dan tidak pula mereka bersedih hati”.

\section{KESIMPULAN}

Ibn Katsir dalam Tafsir al-Qur`an al-Adzim, memang tidak menyampaikan kisah Nabi Adam secara kronolgis melainkan penulis 
yang menyusun ayat dan surah kemudian penafsirannya dari tafsir Ibn Katsir. Dalam al-Qur`an Allah juga menyampaikan kisah Nabi Adam tidak secara runtut dalam sebuah surah melainkan terletak dan tersebar di berbagai surah dan ayat sehingga ada pengulangan pada aneka surah. Namun pengulangan tersebut tidak sepenuhnya sama, melainkan pengulangan itu untuk menguatkan yang sebelumnya.

Oleh karena itu, dengan memperhatikan logika yang ditangkap dan dari deskripsi tafsir Ibn Katsir sendiri ditambah dengan penjelasannya pada buku Qashash al-Anbiya' maka dapat penulis simpulkan bahwa kronologis kisah Nabi Adam As dalam al-Qur`an menurutnya adalah Pertama, penciptaan Nabi Adam. Kedua, kisah Adam As tinggal di surga dengan segala fasilitasnya. Ketiga, kisah Adam As dan istrinya dilarang mendekati pohon kuldi. Menurut Ibn Katsir keluarnya `Adam As dari surga ini dalam dua tahap pertama tahap turun ke langit dunia dan kedua tahap turun ke bumi.

\section{REFERENSI}

Katsir, A. al-F. I. I. bin U. bin. 2017. Tafsir al-Qur'an al-Adzim Jilid 1, 4, 6, 7, 8. (A. dkk Hidayat, Ed.) (3rd ed.). Solo: Insan Kamil.

Nadim, M. 1945. Al-Mu'jam AlMufarras Li Alfazil Qur'an Al-Karim. Mesir: Darul Qutb.

Rofiqoh, A., \& Ansori, I. H. 2017. Kisah-Kisah (Qasas) dalam Al-Qur'an Perspektif I'jaz. QOF , 1, 25-37.

Al-Farmawi, A. A.-H. 2002. Metode Tafsir Maudhu'i. Jakarta: RajaGrafindo Persada.

Maliki. 2018. Tafsir Ibn Katsir: Metode dan Bentuk Penafsirannya. El-Umdah (Jurnal Ilmu Al-Qur`an Dan Tafsir), 1(1), 74-86.

Najib, M. 2015. Kisah Nabi Adam As dalam al-Qur'an (Pendekatan Tafsir Tematik). AL-ITQAN, 1, 105-125.

Parhani, A. 2012. Adam As dalam Perspektif Hadits (Suatu Kajian Tematik Terhadap Hadits Adam Abu alBasyar). Sulesana, 6, 71-72.

Zed, M. 2004. Metode Penelitian Kepustakaan. Jakarta: Yayasan Obor Indonesia. 